\title{
LOS CONVENTOS COLONIALES COMO ESPACIOS LIBERADORES Y DE CREACIÓN ARTÍSTICA PARA LA MUJER
}

\author{
Rima de Vallbona \\ University of Saint Thomas
}

\section{El sistema absolutista de la época y su proyección en el Nuevo Mundo}

Uno de los capítulos más apasionantes de la colonia es el relacionado con la vida conventual en las Indias. Para comprender lo que representaron los conventos en aquella sociedad, hay que tener en cuenta que después de la intensa movilidad social que se produjo en los comienzos de la conquista, al igual que en España y en todas las colonias del imperio, en nuestro suelo se impuso un sistema político-social muy cerrado; un sistema de estratificación engañosamente abierto que admitía el dominio de la nobleza señorial para constituirse sobre ella como poder absoluto bajo cuyo control todo funcionaba. Hasta el tan decantado honor hispánico es parte de este engranaje monárquico-señorial. Al estudiar el teatro de la época, José Antonio de Maravall explica que bajo ese sistema político-social absolutista los temas morales sufrían una gran transformación: el de la victoria del hombre sobre sí mismo y sus instintos, dejaba de ser un vencimiento de las malas inclinaciones de la naturaleza humana. Maravall explica que:

\begin{abstract}
Ahora muy diferentemente, aparece como una victoria sobre los sentimientos personales, con la que se acallan las protestas íntimas y lleva al individuo a asumir por propia voluntad las leyes de un sistema social. Ello exige la creencia de que sólo en el acatamiento a las obligaciones de su puesto en ese sistema de la sociedad aristocrática, se realiza el hombre; no en la fidelidad de una conciencia íntima.'
\end{abstract}

En efecto, según Maravall, se llegaron a controlar las fuerzas íntimas e individuales de los súbditos del imperio al punto que se acataba una línea de conducta por obligación social. Los sentimientos, el amor sobre todo, debían eliminarse porque lo que contaba eran la fama, la opinión de los otros y atenerse cada uno al puesto que se le había asignado en la estratificación social.

La vida en el Nuevo Mundo no escapó al dominio absolutista a pesar de que la distancia suavizaba a veces las consecuencias. Si echamos un ligero vistazo a la época colonial se puede observar cómo el gobierno establecía leyes muy estrictas relativas a las parejas y los matrimo- 
nios. Ordenaba, por ejemplo, al principio, que los matrimonios se llevaran a cabo sólo entre miembros de la raza ibérica y la indígena/mestiza: aquellos que se casaban con negras recibían como castigo no ser promovidos más allá de determinada categoría. Casarse con mujeres mulatas o de ínfima condición social, era una ofensa para la corona, la cual era sancionada también con dureza. ${ }^{2}$ El control del poder monárquico sobre el individuo, su vida sentimental y personal fue tanto, que las viudas de encomenderos eran obligadas a casarse casi tan pronto como habían terminado de echar tierra al cadáver de su esposo; sólo Doña María de Escobar, acaudalada viuda de gran influencia política, logró burlar la autoridad y permanecer sin casarse ipor tercera vez! durante un período de tres años, el más largo que se ha registrado en la historia de las Indias. ${ }^{3}$

\section{Necesidad de fundar conventos en el Nuevo Mundo}

El establecimiento de conventos y recogimientos de mujeres fue el resultado de este rígido control gubernamental en las Indias. En los principios de la conquista hubo gran escasez de mujeres. Ninguna se embarcó en la primera ni la segunda expediciones de Colón. En realidad las primeras españolas en el Nuevo Mundo fueron las treinta que vinieron en el tercer viaje de Colón (1497-1498); en éste embarcaron 330 hombres. ${ }^{4}$. En esas aventuras exploradoras fueron tan pocas las acompañantes de conquistadores y colonizadores, que no llegaban a más de una por cada diez hombres. Según Bernal Díaz del Castillo, en la expedición de Hernán Cortés a México se hallaba sólo una mujer; y en el banquete que se dio en celebración de la conquista de México, tomaron parte sólo ocho españolas ${ }^{5}$; después llegó la esposa de Cortés con su hermana y otras, casadas, que venían a unirse con sus maridos ${ }^{6}$. En su expedición para conquistar Costa Rica, el gobernador Diego de Artieda en 1575 llevó 275 hombres y 58 mujeres ${ }^{7}$.

Sin embargo, medio siglo después de iniciada la conquista, un virrey da noticias de que había exceso de mujeres y que muchas muy pobres estaban formulando peticiones con insistencia para salir de España. Para las de la clase privilegiada de esa sociedad sólo había dos caminos en la vida, casarse o hacerse monjas. Así, la autoridad tuvo que tomar medidas y comenzar a hacer gestiones con el fin de fundar conventos para que en ellos se recogieran "hijas de conquistadores y doncellas pobres y huérfanas que al no tener este refugio sería lastimosa su perdición" en México, en 1542 se solicitó permiso para fundar dos conventos de monjas pues "existía gran número de muchachas, hijas legítimas e hijas naturales de españoles distinguidos y honorables que no podían casarse". ${ }^{9}$ A partir de entonces surgieron otros conventos que cumplían con el cometido de salvar a las mujeres de los peligros que las acechaban al quedar solteras en su casa.

La política de entonces que se puede resumir en el lema de poblar es fundar, fue reacia para establecer tales conventos o casas de recogimientos. Entonces se dieron casos en que se estimulaba a los españoles de Chile para ir al Perú en busca de esposa debido a la escasez de mujeres en esa región. En cambio existían órdenes muy estrictas para impedir por todos los medios la emigración de mujeres al Perú: en 1565 el licenciado Castro comenta que en el Perú había tal exceso de mujeres, que se difundió la norma de pedirles aportar al matrimonio altísimas sumas de dinero como dote, lo cual representaba un impedimento para una gran mayoría, sobre todo 
para criollas y mestizas hijas de pobres viudas de conquistadores. ${ }^{10}$ Un virrey del Perú, escandalizado por haber visto "las muchas ofensas contra Nuestro Señor que [...] se aumentaba en materia de sensualidad", decide procurar un "recogimiento para mujeres distraídas", "perniciosas e insolentes, tanto para castigar [las] con clausura, cuanto para amedrentar a las demás". "Por muchas medidas que se tomaron, la prostitución llegó a tales extremos, que por real cédula del 21 de agosto de 1526 el rey concedió licencia a Juan Sánchez Sarmiento para edificar en el Nuevo Mundo un prostíbulo, porque "porla onestidad de la ciudad e mujeres casadas [de Santo Domingo...] e por escusar otros daños e inconvenientes hay necesidad que se haga casa de mujeres públicas". Lo irónico es que además de la firma del rey, que concede la licencia, el documento lleva las de los obispos de Osma, Canarias y Ciudad Rodrigo. ${ }^{12}$

Así las cosas, a los obispos de Nueva España que solicitaron permiso de comenzar a fundar conventos, se les respondió en real cédula del 23 de agosto de 1538: "Decís que os parece cosa muy provechosa y necesaria para la instrucción de las hijas de los naturales, que haya en esta ciudad de México un monasterio de monjas profesas [... sin embargo] aquí ha parecido que por ahora no debe haber en las Indias monasterios de monjas". No obstante, al final de la época colonial había sólo en el virreinato de Nueva España más de 2400 monjas. ${ }^{13}$ En Bahía, Brasil, de 160 hijas nacidas en 53 familias prominentes entre 1680 y 1795, más del 77\% (107) entraron al convento, el $14 \%$ se casaron y el $5 \%$ quedaron solteras, según informes de la socióloga Susan A. Soeiro ${ }^{14}$.

\section{Los conventos coloniales, espacios de liberación femenina en una sociedad cerrada}

En aquellos tiempos en que las armas y la religión dominaban la vida hispánica, constituía una verdadera distinción tener un pariente cercano en el ejército y también en la iglesia. Al referirse a los que se dedican a la vida religiosa, la socióloga Asunción Lavrin dice que "esta clase espiritual privilegiada constituía también una minoría social privilegiada debido al carácter restrictivo que tenían las reglas de admisión de los conventos". Aquí hay que recordar que para entrar a los conventos, se debía dar pruebas de limpieza de sangre o de que se procedía de familia de cristianos viejos sin ningún proceso inquisitorial. ${ }^{15}$

Pone en relieve la reclusión en que vivían en el hogar, el dicho de que las mujeres salían de su casa sólo en tres señaladas ocasiones, para su bautismo, para su boda y para su entierro. Siendo esto una realidad, conviene analizar entonces las funciones que los conventos cumplían para que las mujeres prefirieran el claustro a la vida hogareña. Considerando las costumbres de la época, es obvio que estas funciones representan relativas formas de liberación femenina:

1. Eran los conventos coloniales refugio para una auténtica vocación religiosa.

2. Proveían amparo, seguridad y solaz a las que no podían casarse.

3. Constituían verdaderos centros de finanzas.

4. Patrocinaban la actividad intelectual y artística.

Las 3 primeras funciones se verán ligeramente con el fin de abarcar con más profundidad la de la actividad intelectual y creativa. 


\subsection{Los conventos coloniales, refugio para una auténtica vocación religiosa}

La más importante y lógica de todas las funciones del convento era la de satisfacer las apetencias espirituales de algunas mujeres con verdadera vocación religiosa. A la cabeza de todas, tenemos a la Beata Madre Francisca Josepha del Castillo, conocida como la Madre Castillo de Colombia, a quien Menéndez y Pelayo comparó con Santa Teresa ${ }^{16}$ Otras que pasaron por la experiencia místico-asceta, hicieron milagros y tuvieron visiones celestiales, fueron la Beata Vitória Encarnaçao de Brasil; de México, Sor Jacinta de San José, Sor María Lino de la Canal, Sor María Anna Agueda de San Ignacio, Sor Sebastiana Josepha de la S.S. Trinidad. En Guatemala, doña Anna Guerra de Jesús (1639-1713) fue canonizada. En honor a la verdad, hacer una lista de estas monjas de fervorosa vida religiosa, resultaría interminable. Esto queda como testimonio de que persistió un auténtico espíritu místico que contrasta con ese frívolo ambiente dominado por predicadores de retórica vacía, por un pueblo supersticioso ávido de milagros y revelaciones y por inflexibles inquisidores que implantaron en nuestro suelo cruentas hogueras y autos de fe. Precisamente por la abundancia de beatas y santas, bien se puede decir que no todas las mujeres entraban al convento sin vocación religiosa para soterrar los pecados o llevar una doble vida, hipócritamente honesta.

Con tanta represión y constante control socio-moral del imperialismo español no resulta nada extraño que muchas mujeres buscaran escapar de la realidad por diversas vías, y que una de ellas fuera la del ascetismo y misticismo. Mágico mundo el de las Indias en el que el vulgo escapaba también creyendo en portentosos milagros con los que estaba familiarizado como lo estaba con las increíbles hazañas de los conquistadores, las cuales se equiparaban a las de la caballería andante de la literatura en boga.

\subsection{Los conventos como amparo, seguridad y solaz para las mujeres que no podían casarse}

Durante la colonia se dieron situaciones en las que una mujer no podía casarse porque no tenía pretendiente, o porque no lograba aportar una adecuada dote al matrimonio: a veces, por venir de una familia aristocrática, pero pobre; otras, porque los medios económicos, aunque considerables, no eran suficientes para cubrir las dotes de todas las hijas casaderas. En estos casos los conventos cumplían una doble función: la de salvaguardar la tan decantada honra hispánica, y la de prevenir la prostitución y otros excesos que hubiesen traído el caos en aquella incipiente sociedad tan rigurosamente estructurada.

Aunque el convento era una forma de renunciar a la vida secular, para muchas no representaba llevar una vida piadosa. Algunas vivían rodeadas de sus amistades y parientes; además, llevaban consigo por lo menos dos esclavas para su servicio y unas cuantas criadas. Por supuesto, esto hacía que muchas no tuvieran verdadera vocación religiosa y por lo mismo hacían caso omiso de los votos de obediencia, castidad y pobreza... y la regla de la clausura, se la metían en el bolsillo... Estas religiosas llevaban un género de vida "más próximo a la comodidad de la vida cortesana que al ascetismo previsto por las severas reglas dictadas por los fundadores". Además, a finales del siglo XVII el Arzobispo Fray Payo de Ribera "autorizó a las religiosas a vivir en celdas individuales, administrar particularmente sus ingresos y disponer de las rentas de sus capitales." ${ }^{17}$ Se han recogido datos muy interesantes de que cuando había restricciones u órdenes en contra de esas libertades, las religiosas burlaban sus votos: 
En cuanto al voto de obediencia, se tienen noticias de motines de monjas como el de 1660 en el que las franciscanas de Nueva España se opusieron con firmeza a que se les restringiera el número de sirvientas que podían llevar al convento. Gonzalbo Aizpuru comenta que debido a la oposición de las religiosas, en la ciudad de Puebla se tuvo que llegar a la violencia para imponer la vida comunitaria en los conventos. Así, en el de Santa Inés intervino hasta el ejército para derribar las paredes que separaban las celdas individuales. ${ }^{18}$ En 1701 al Arzobispo de México se le llamó urgentemente "para calmar un 'motín' de las monjas de La Concepción, quienes se habían rebelado contra su abadesa”. En 1660, las franciscanas se opusieron con firmeza y gran éxito a la restricción que se les quiso imponer del número de sirvientas. A decir verdad, abundan los documentos que recogen estos actos subversivos de las religiosas. ${ }^{19}$

La imposición de la vida comunal y las limitaciones del número de sirvientes y esclavos representaban una reforma necesaria para despertar el espíritu de unión y fraternidad del que carecían algunas órdenes religosas ya que cada cual velaba sólo por su bienestar personal sin ningún sentido de solidaridad. Cuando entra la Madre Castillo al convento, cuenta que estaba tan pobre que no podía pagar el costo de una celda, de modo que se echaba a dormir en los corredores, expuesta a la intemperie; se alimentaba con pétalos de rosa, y mientras ella iba languideciendo de hambre, las otras monjas, carentes de sentido cristiano, no compartían con ella los manjares de su mesa. Pone más en relieve este egoísmo el hecho de que cuatro años antes de venir al mundo la Madre Castillo, "murió en olor de santidad la tunjana doña Antonia de Cabañas, quien no pudo ingresar al convento por su extremada pobreza". ${ }^{20}$

El voto de castidad exigía a las religiosas consagrarse totalmente a una vida de pureza dedicada sólo a Dios. Aunque la virginidad era una virtud muy considerada en la aceptación de una monja al convento, muchas viudas y mujeres separadas de sus maridos profesaban también. A pesar de todas las reglas y medidas para mantener un estado constante de virtud, es sabido que durante los siglos XVII y XVIII era corriente que las monjas tuvieran relaciones muy personales con otros religiosos, clérigos y seglares. Estas se conocían con el nombre de devociones y representaban una curiosa forma de cortejo en el confesionario o por la rejilla, intercambio de cartas y regalos y en casos extremos, una relación carnal. Estos amores ilícitos han sido recogidos en la literatura hispánica por el Arcipreste de Hita, Quevedo y algunos escritores del Nuevo Mundo, los cuales, en forma satírica, llegaron a llamar a esas religiosas "monjas lascivas". Después de un serio estudio, Asunción Lavrin aclara que los casos extremos ocurrieron con menos frecuencia de lo que la maledicencia ha divulgado. Sí fue muy frecuente el trato constante con el mundo de afuera. Por ejemplo, aunque del convento de Santa Clara de Tunja en Colombia se dijo que era sombrío, pero "si allí acudían las gentes del mundo, no era para entregarse a [...] serenos coloquios [...], sino para simular rencillas, para llevar la posta de los chismes de la villa y para entremeter a los seglares en los comicios abaciales". ${ }^{21}$ En este ambiente que era el de su convento, no es de sorprenderse que La Madre Castillo haya contado en su texto autobiográfico que vio "el domonio en figura de fraile", el cual entró en la celda de una monja. Y lo irónico es que al día siguiente la Madre Castillo no se explica por qué esa misma monja le arma una bronca mayúscula en la que envuelve contra ella a seglares, criadas y novicias. ${ }^{22}$

Se suponía que aquellas mujeres llevaban una vida de enclaustramiento y de virtud, pero por mucho que las autoridades eclesiásticas buscaron todos los medios posibles para evitar los abusos, el resultado está en los documentos diocesanos: Lavrin explica que ese firme propósito 
fracasó por el carácter mundano que se exponía en las porterías de gran parte de los conventos de siglos XVII y XVIII en México. En aquellas porterías toda clase de personas se aglomeraban -sirvientes, mandaderos, vendedores, visitantes y confesores. Se vendían mercancías; se recibían visitas; los criados llevaban a cabo sus propios negocios; se servían refrescos a los visitantes y a veces hasta música y representaciones teatrales tenían lugar. ${ }^{23}$

Pese a todos los esfuerzos de los reformistas eclesiásticos, se sabe que aún durante el siglo XIX las porterías monjiles se caracterizaban por ese mundanal ruido y movimiento. Las monjas

no habían perdido su interés en las cosas mundanas y estaban muy enteradas de los acontecimientos ciudadanos: bodas, bautizos, robos, llegada de nuevos funcionarios. Y aunque no podían salir de los conventos, tenían criadas que se pasaban el día en la calle y les contaban a sus amas las últimas novedades. ${ }^{24}$

En Perú, por ejemplo, había más de mil habitantes en algunos conventos. Así, éstos eran esencialmente ciudades de mujeres seculares. ${ }^{25}$ "En esta clase de conventos las monjas vestían con elegancia, se dedicaban a la vida social y comían manjares preparados para ellas por sus propias sirvientas y esclavas". Algunas usaban trajes de moda con adornos supérfluos. Los obispos los censuraban diciendo que dichos trajes en las monjas

no se pueden escusar de pecado venial [...pues los visten] a fin de parecer bien y enamorar a los hombres con quien hablan, certíssimamente son pecado mortal. ¿Qué pecado será añadir a essa profanidad en Esposas de Jesuchristo el afeytarse, el escotarse y el llevar el pelo arreglado, y más siendo a la visita

En 1694 Fray Raimundo Lumbier condenaba esas y otras costumbres disueltas, como la de jugar naipes y dados apostando "cosa de valor" y "alhajuelas" propias. ${ }^{26}$ Ilustra lo anterior sor Juana de Maldonado y Paz, quien se aplicaba los más caros cosméticos y usaba siempre el hábito de seda con finos encajes de Flandes.

\subsection{Los conventos como centros de finanzas}

En el convento do Desterro en Brasil, la dote que se pedía en éste (como en muchos otros conventos) era tan exorbitante que sólo las doncellas muy ricas podían entrar. Como la dote era preciso pagarla al contado, muchos padres asumían una hipoteca sobre su propiedad y se comprometían a pagar la deuda ellos mismos, sus herederos, o quienes en el futuro se quedaran con sus bienes, lo que representaba una deuda infinita. Así las cosas, el convento llegó a enriquecerse de tal manera, que "también operaba como una institución de préstamos, y colocar una hija en él facilitaba la obtención de crédito", con lo que se conservaba la posición económica de la familia. Además, "las dotes de las monjas y sus testamentos a favor del convento en que profesaban mantenían permanentemente el proceso de incremento del capital fundamental"27.

Se sabe también que algunas monjas tenían permiso de poseer propiedades y percibir una considerable renta anual llamada reserva para sus gastos personales. Se les dejaba también comprar o vender la celda en que vivían por sumas que montaban de setecientos a dos mil pe- 
sos; cuando no había celda, la hacían construir los padres o protectores de la novicia, a veces con el lujo de verdaderos palacetes como la de Sor Juana de Maldonado y Paz de Guatemala. En México. Las piadosas y místicas se quejaban en algunos conventos de que sus compañeras vivían "absorbidas por negocios materiales". Existen evidencias de que las concepcionistas de México

tenían una compleja administración de capitales y rentas, la comunidad era dueña de numerosas propiedades y las religiosas, que hacían testamento antes de profesar, conservaban el usufructo de algunas rentas y, eventualmente, podían disponer de su capital para comprar o cambiar la celda en la que vivían, ayudar a algún familiar o fundar alguna obra pía. ${ }^{28}$

Susan A. Soeiro informa que algunas monjas se metieron a prestamistas. Entre ellas, la Madre Catarina de Monte Sinaí quien se dedicó a este negocio y fue la religiosa más rica del convento do Desterro en Brasil: cuando murió, sus bienes montaban a la suma de 4.402.000 reales. ${ }^{29}$ Sin embargo, se ha comprobado que en algunos casos había gran contraste entre "las estrecheces que pasaban las religiosas y las riquezas que poseían los conventos", debido en parte al sistema de inversión de capitales que rendía sólo un 5\%, el cual generalmente se cobraba tarde y a veces nunca. ${ }^{30}$

\subsection{Los conventos coloniales, ámbitos que favorecían la vida intelectual y creativa del Nuevo Mundo}

Partiendo de las ideas de Leibnitz, quien declaraba que el género humano se reformaría "si se reformase la educación de la mujer", en su libro sobre la educación en Nueva España, Gonzalbo Aizpuru revisa las ideas de la ilustración sobre dicho tema: en realidad hubo varios defensores de la capacidad intelectual de la mujer, entre los que cuentan Feijóo, Fernández Lizardi, Sánchez de Barquera, Josefa Amar y Borbón y otros. ${ }^{31}$ Pese a esto, al revisar las páginas de la autobiografía de la Madre Castillo, el crítico Achury Valenzuela dice que a través de esas páginas se puede columbrar la pobre vida intelectual y moral de muchas que se refugiaban en los conventos. En general estas monjas no recibían educación formal, igual que la mayoría de las mujeres de la colonia. Por su parte, Asunción Lavrin informa que muchas monjas sabían leer porque tenían que dedicar parte de su tiempo a las lecturas devotas; algunas medio escribían, y en muy pocos conventos se exigía que las monjas supieran suficiente latín para rezar. ${ }^{32}$

Por supuesto, el patriarcalismo imperante de entonces llegó a tal punto, que cuando los textos de una mujer que usara seudónimo se destacaban y se reconocía que eran superiores en calidad a los de sus contemporáneos masculinos, los críticos en general afirmaron que tras esos tres apelativos ficticios se ocultaban hombres. Ejemplifican esta discriminación los casos de Teresa Margarida Da Silva e Orta del Brasil y Clarinda y Amarilis del Perú. ¿Razones para negarles el derecho de autoría? Alegaban que las mujeres de esos tiempos no tenían la formación ni la capacidad intelectual para realizar valiosas creaciones. Veamos ahora, a grandes pinceladas, sus méritos:

Teresa Margarida Da Silva e Orta, es el anagrama de Dorothea Engrassia Tavareda d'Almira autora de Las aventuras de Diófanes. A este texto se le ha considerado precursor de la 
novela brasileña, o por lo menos tentativa aislada de novela sin continuadores, pues surgió un siglo antes de las novelas de Texeira e Soussa y de Macedo. ${ }^{33}$ Después de un estudio documentado del libro en cuestión, el crítico Ernesto Ennes concluye que la autoría del mismo le pertenece en realidad a Teresa Margarida, pero que "la paternidad espiritual de la obra se le debe a Alexandre de Guzmao" ${ }^{34}$ En cuanto a Clarinda, se le llamó la "Gran Anónima" y se dio a conocer por su poema "Discurso en loor de la poesía". Este fue incluido por Diego de Mexía en su Parnaso antártico, en el que "explica que su autora es una señora muy principal de este Reino [de Perú], muy versada en la lengua toscana y portuguesa, por cuyo mandamiento y por justos respetos no se escribe su nombre". ${ }^{35}$ Menéndez y Pelayo considera que es "un curioso ensayo de "poética', como un bello trozo de inspiración didáctica". ${ }^{36}$ El poeta colombiano Rafael Pombo afirma que "rara vez en castellano se ha discurrido más alta y prácticamente sobre la poesía" como en el poema de Clarinda ${ }^{37} \mathrm{El}$ caso de Amarilis, el tercer seudónimo, lo revisaré más adelante, entre las monjas poetas.

Lo irónico e interesante es que en este ambiente poco apto para la vida intelectual y que a la vez era reacio para reconocer el talento de la mujer en el Nuevo Mundo, las monjas efectuaron una riquísima labor creativa digna de ser considerada. En especial vale la pena concentrarse en la producción literaria que salió de esos conventos.

Sobresale entre todas ellas la sin par mexicana Sor Juana Inés de la Cruz (1648?-1695), la Décima Musa de nuestro continente: los cuatro mil volúmenes o más que poseía y los instrumentos matemáticos y musicales hicieron de su celda un pequeño mundo intelectual que era la atracción de la corte de los virreyes y de los hombres más afamados. Sin embargo, en esa era conflictiva prevalecía una extremada desconfianza ante toda actividad científica; por lo mismo, sor Juan Inés se destaca como una figura solitaria cuyo genio se dedicó al examen y reflexión de los fenómenos que iba observando, y de los experimentos que anticipaban ya el espíritu cartesiano del Siglo de las Luces. Gran feminista, fue considerada por la crítica desde el siglo XVII entre los grandes genios de la poesía barroca. Además, sobresalió también en el teatro y hasta en prosa. Su obra completa, recogida en cuatro voluminosos tomos por Méndez Plancarte, abarca, Lírica personal, Villancicos y letras sacras, Autos y loas y Comedias, sainetes y prosa. ${ }^{38}$

En cambio, los textos de la Madre Castillo no corrieron la suerte de los de sor Juana, pues la primera edición de sus libros tuvo que esperar un siglo; la segunda, otro siglo más. Menéndez y Pelayo la llamó la Santa Teresa de América y con razón: no sólo se entregó a la vida mística como la santa de Avila, sino también escribió su propia vida a instancias de sus confesores. Además, su obra místico-literaria lleva el sello y la influencia obvia de Santa Teresa y aunque no alcanzó a ser canonizada, sí se le beatificó. Su producción literaria, recogida y publicada en 1968 por Darío Achury Valenzuela, se reduce a Vida de la Madre Francisca Josefa de la Concepción..., escrita por ella misma de orden de sus confesores, conocida como su Vida y publicada en Filadelfia en 1817; y Afectos espirituales, que se publicó en Bogotá en 1843, tratado místico en el que la exposición no es sistemática ni doctrinal, sino afectiva ${ }^{39}$ Entre sus textos inéditos cuenta el manuscrito llamado Cuaderno de Enciso con poemas que se le atribuyen a ella, pero Méndez Plancarte ha demostrado que algunos son adaptaciones de textos de sor Juana Inés de la Cruz. ${ }^{40}$ Así, aunque la Madre Castillo ya tiene asegurado un lugar en la prosa del continente, queda la tarea de comprobar si en efecto su obra se le puede incluir también en la lírica de aquellos tiempos. 
Es en Santo Domingo, conocida durante la época colonial como la Atenas del Nuevo Mundo, donde nace y escribe sobre temas religiosos la primera poeta mística que se puede considerar con seriedad en las letras del continente: sor Leonor de Ovando (?- 1610?), quien profesó en el Monasterio de Regina. Fue calificada por Eugenio de Salazar en su Silva de poesía como "ingeniosa poeta y muy religiosa observante". ${ }^{41}$ De ella se conservan sólo cinco sonetos y una composición escrita en versos blancos. ${ }^{42}$

En su libro, A New Survey of the West Indies (1655), Thomas Gage dio por primera vez noticias de la "Décima Musa" guatemalteca, sor Juana de Maldonado y Paz (1595-1665?). Desde entonces se ha venido incluyendo su nombre en las historias de la literatura de Guatemala. ${ }^{43}$ No obstante, hasta hace poco no se tenía de ella un solo poema como prueba de su talento para asignarle ese puesto en la lírica de su país. Fueron las serias investigaciones de Ernesto Chinchilla Aguilar y Mariano López Mayorical las que dieron a luz documentos fehacientes que confirmaron como históricas las afirmaciones de Gage, las cuales parecían pertenecer al ámbito de la leyenda por lo extraordinarias. Entre ellas cuentan el rico palacete que poseía sor Juana en el convento de la Concepción de Santiago de los Caballeros, en Guatemala; las protestas que levantó en toda la ciudad su nombramiento como abadesa del convento; el cuadro en el que sor Juana fue pintada por Montúfar como Santa Lucía, el cual estaba expuesto en la capilla de su padre, y fue condenado por la inquisición; su celda, afamado centro donde se dieron cita los más prestigiosos sabios, poetas, artistas, intelecuales, contemporáneos suyos. ${ }^{44}$ Thomas Gage afirmaba que ella "era verdaderamente una de las nueve musas y una Calíope para improvisar versos". Sin embargo, los poemas de ella que Fray antonio de Arochena menciona en su Catálogo de los escritores del orden de San Franciso de la Provincia de Guatemala, no se han podido localizar. Lo poco que se ha rescatado hasta el momento no da prueba suficiente de un excepcional talento literario. Queda mucho por investigar todavía para llegar a una conclusión definitiva.

En el capítulo de la poesía mística, cuentan muchas monjas más. Son dignas de mencionar: sor María de los Angeles, quien en el mundo se llamó María Josefa Paz del Castillo (1750-?) y profesó de carmelita en Venezuela; ${ }^{45}$ la capuchina sor Juana de Hazaña y la mercedaria descalza, sor Paula de Jesús. De estas dos se tienen noticias gracias a los poemas suyos que recogió Rubén Vargas Ugarte en la antología titulada Clásicos peruanos. ${ }^{46}$

A raíz del desbordamiento del río Mapocho en 1783, sor Tadea de San Joaquín, conocida también como Tadea García de la Huerta (?-1827) escribió un largo romance a su confesor, quien estaba ausente de la ciudad. En él le relata cómo peligraron las vidas de las monjas de su Monasterio del Carmen de San Rafael cuando las aguas del río se estrellaron contra las murallas del edificio. El romance fue publicado en Lima en 1784 bajo el título de "Relación de la inundación que hizo el río Mapocho de la ciudad de Santiago de Chile en el Monasterio de las Carmelitas". ${ }^{47}$ Se considera el primer poema escrito por una mujer chilena. ${ }^{48}$

De Amarilis sólo se conserva una excelente silva titulada "Epístola a Belardo", la cual envió a Lope de Vega en 1621. En ella le solicita que escriba la biografía de Santa Dorotea; le cuenta que ella es descendiente de conquistadores del Perú, los cuales fueron, a su vez, dos de los fundadores de Huánuco, los Tello de Sotomayor; le explica que está en un convento de.Lima; y finalmente le expresa su tendencia a amar con osadía los bienes "que son más imposibles" entre los que cuenta "el amor sin esperanza" que él, Lope de Vega, despertó en ella con sus "soberanas obras". En 1621 la publicó por primera vez el Fénix de los Ingenios en La Filo- 
mena y en 1630 la incluyó en su Laurel de Apolo. La alta calidad del poema ha sido unánimemente reconocida por rigurosos críticos como Menéndez y Pelayo.

Fueron también las monjas quienes escribieron autobiografías en las que dejaron tetimonios de una vida espiritual muy rica y paralela a la que vivieron los místicos de la Metrópoli. Algunas de estas páginas son inéditas; otras, de dudoso valor literario tienen el mérito de suministrar información socio-histórica relativa a los espacios conventuales. Cuentan entre estos textos la Carta athenagórica o Respuesta de la poetisa a la muy ilustre sor Filotea de la Cruz (alias obispo de Puebla, Nueva España), corta e importante autobiografía de Sor Juana Inés. La Vida de la Madre Castillo, antes mencionada, es un texto desordenado, digresivo, lleno de detalles que retardan la narración y en algunos pasajes la vuelven prosaica; sin embargo, la sinceridad y candidez religiosa de la autora prestan amenidad a la lectura. Vida de la Madre María Marcela, religiosa capuchina del Convento de Querétaro, escrita por orden de su confesor, detalla los arrebatos místicos de dicha monja mexicana (1759-?); el texto manuscrito, inédito, (aunque se pueden leer algunos pasajes en Untold Sister - Hispanic Nuns in Their Own Works ${ }^{49}$ se conserva en la Biblioteca Nacional de México. Igualmente inédita y escrita en el siglo XVIII en forma de epístolas, permanece en la misma biblioteca la de sor Sebastiana Josefa, la cual lleva por título, Cartas en las quales manifiesta a su confesor las cosas interiores y exteriores de su vida la V.M. Sor Sebastiana Josepha de la Santísima Trinidad (? -murió el 4 de octubre de 1757, según consta en la carta $\mathrm{N}^{\circ} 50$, folio 313); fue religiosa de velo negro del Convento de San Juan de la Penitencia de México; el texto de sor Sebastiana Josefa tiene la particularidad de incluir poemas místicoeróticos combinados con la prosa; ${ }^{50}$ queda la tarea de comprobar si son de su autoría o no.

Poseída del espíritu místico-febril de aquel entonces, sor Ursula Suárez (1668-1749) de Chile, escribió Relación de las singulares misericordias que el Señor ha usado con una religiosa, indigna esposa suya. Sin embargo, según José Toribio Medina, ese libro "no contiene más que la historia de sus propias imaginaciones". ${ }^{51}$ A decir verdad, en la literatura de esos tiempos persiste un patrón de realidad entreverado con la fantasía, tanto en la literatura devota, como en las crónicas de la conquista.

Igualmente escribió su vida sor María Anna Agueda de San Ignacio (1695-1756), fundadora del convento de dominicas recoletas de Santa Rosa de la Puebla de los Angeles, México; la publicó en 1758 el padre José Bellido. ${ }^{52}$ Toda la obra de Sor María Anna Agueda de San Ignacio fue publicada con dinero del obispo de Puebla, fray Domingo Alvarez de Abreu (también los obispos tienen sus debilidades); es cierto que Sor María Anna escribía con sinceridad, pero para hacerse una idea de la pobre calidad de cierta literatura devota de aquellos tiempos, transcribo sólo una pequeña parte del título de uno de sus libros: Mar de gracias, que comunicó el Altíssimo a María Santíssima, Madre del Divino Verbo Humanado, en la leche puríssima de sus virginales pechos con que le alimentó en su infancia, y se conservó hasta que murió en la Cruz, difundiéndola en raudales de Sangre, para remedio de los pobres míseros hijos de Adán. ${ }^{53}$ El padre Mariano Cuevas considera este libro un "esperpento" y con sorna comenta que a pesar de no tener ningún valor literario ni religioso, llegó a reiprimirse "y los obispos, tan quitados de la pena". Los privilegios que gozó Sor María Anna son prueba de las arbitrariedades y errores cometidos por el poder eclesiástico masculino de la época: echaron al fuego textos que debieron ser salvados, prohibieron a veces la actividad intelectual como en el caso de Sor Juana Inés de la Cruz y otras, dieron a la luz pública textos sin valor alguno. 
De gran interés es la autobiografía de la madre Inés de la Cruz (1570-1633), fundadora del convento de San José de carmelitas descalzas, la cual fue publicada por Sigüenza y Góngora en su Parayso occidental..$^{54} \mathrm{El}$ Ecuador cuenta con la de sor Catalina de Jesús María Herrera (1717-1795), la cual lleva por título Secretos entre el alma y Dios.

En resumen, los conventos de la época colonial en muchas ocasiones representaron una magnífica oportunidad para que las mujeres se independizaran de las imposiciones de la sociedad; de las demandas de los hombres (padres, hermanos, maridos) y su obsesiva "honra"; además, para que se realizaran en áreas prohibidas o restringidas para ellas fuera del convento. Arenal y Schlau afirman que pese a las reglamentaciones y restricciones de esos centros religiosos, las monjas lograron forjar una subcultura que representaba una alternativa más favorable que la que les ofrecían sus hogares, puesto que ahí podían ejercer y hasta desarrollar sus talentos. Ambas autoras opinan que la separación de los hombres daba a las mujeres un sentido de poder y a la vez las motivaba para expresarse de manera creativa; así fue como las letras, la música y las artes se enriquecieron con su aporte.

Para las que se ejercieron en el misticismo, el cual tradicionalmente se ha expresado en imágenes sensuales y eróticas, los conventos fueron también espacios liberadores: al reprimir las monjas su sexualidad en el mundo real "y darle rienda suelta en la imaginación erótica, se sometieron al control de la Iglesia, pero paradójicamente adquirieron para ellas mismas el autoconocimiento, placer, independencia y prestigio que las seculares nunca lograron". 55

En otras palabras, muchos conventos de la colonia fueron verdaderos centros de liberación femenina. Son abundantes los documentos de la época que lo atestiguan. Y si todavía hubiera dudas, este curioso fenómeno de encierro-prohibición / apertura-liberación resulta más evidente en la carta del Padre Provincial de la orden de frailes menores de Nueva España: la dirige a la Abadesa y Portera de su orden urgiéndole que obligue a las religiosas a mantener mayor recato y encierro. Lo que resulta más significativo, es que en ella el religioso critica la libertad que hay en los conventos, la cual "de ninguna manera se les permitiría a las que habitan en las casas de sus padres". ${ }^{56}$ Los deplorables abusos y excesos de las religiosas, llevaron a algunos clérigos a realizar una reforma conventual, ya que "aparentemente, la vida en el claustro era tan atractiva que muchas mujeres abandonaban a sus maridos confiadas en que encontrarían refugio en la celda de alguna amiga o parienta profesa en una orden religiosa". ${ }^{57}$

\section{Notas}

1. José Antonio Maravall, Teatro y literatura en la sociedad barroca (Madrid: seminarios y Ediciones, S.A., 1972): pp. 97-98.

2. C.R. Boxer, "Spanish and Portuguese America" en Women in Iberian Expansion Overseas 1415-1815. Some Facts, Fanbcies, and Personalities (New York: Oxford University Press, 1975): pp. 37-38.

3. C.R. Boxer, "Spanish and Portuguese America": p.45 y James lockhart y Enrique Otte "Spanish Women and the Second Generation" en Letters and People of the Spanish Indies - Sixteen Century ( Cambridge: Cambrige University Press, 1976): pp. 157-58.

4. Richard Konetzke "La emigración de mujeres españolas a América”, Revista Internacional de Sociología, 9 (enero-marzo, 1945): p.124. 
5. Bernal Díaz del Castillo: Tomo II: p. 149.

6. Bernal Díaz del Castillo: Tomo II: p. 192.

7. Richard Konetzke, “La emigración”: p. 147.

8. Gobernantes del Perú, tomo 15: p.97, citado por Richard Konetzke, "La emigración de mujeres”: p.149.

9. Jiménez de la Espada, "Carta al Emperador del 3 de noviembre de 1556" en Relaciones geográficas, I, apéndice: CIV, y "Escrito de la Audiencia de Charcas al rey, 14 de febrero 1557, La Audiencia de Charcvas, tomo I: p.442 citada por Richard Konetzke, "La emigración de mujeres”: p.148.

10. "Carta del Virrey Conde del Villar", 25 abril de 1588, en Gobernates del Perú, tomo 10: p.69. Citada por Richard Konetzke, "La emigración de mujeres": p.133.

11. "Carta del Virrey": p.133.

12. "Real Cédula que manda que habiendo necesidad se puedan establecer casas de mujeres públicas en al ciudad de Santo Domingo (Isla Española), Archivo de Indias, 139-1-7. lib.11, folio 140.

13. Pilar Gonzalbo Aizpuru, Las mujeres en la Nueva España - Educación y vida cotidiana. (México: El Colegio de México. A.C., 1987): p.123. Asunción Lavrin, "Values and Meaning of Monastic Life for Nuns in Colonial Mexico." Catholic Historical Review, 3 (Octubre, 1958): p. 367.

14. Susan A. Soeiro, "The Social and Econimic Role of the Convent: Women and Nuns in Colonial Bahía 1667-1800.” Hispanic American Historical Review, 2 (1974): p. 214.

15. Asunción Lavrin, "Values and Meaning,": 367 y 372. Pilar Gonzalbo Aizpuru, Las mujeres en la Nueva España - Educación y vida cotidiana (México D.F.: El Colegio de México, 1987): p. 215, 219-20.

16. Marcelino Menéndez Pelayo, Poesía hispano-americana, tomo I (Madrid: Librería General de Victoriano Suárez, 1911): 196.

17. Pilar Gonzalbo Aizpuru, Las mujeres: pp. 227 y 239.

18. Pilar Gonzalbo Aizpuru, Las mujeres: pp. 247-48; también p. 245.

19. Asunción Lavrin, "Values and Meaning": pp. 373-74.

20. Darío Achury Valenzuela, "Introducción" a la Madre Francisca Josefa de la Concepción de Castillo, Obras Completas, 2 Vols. (Bogotá: Talleres Gráficos del Banco de la República, 1968).

21. Darío Achury Valenzuela, "Introducción”: p. CLXXXVII. R. Vallbona / Conventos coloniales.

22. Madre Castillo, Obras completas, volumen I, capítulo XXV.

23. Asunción Lavrin, "Values and meaning,": p. 378.

24. Raquel Chang-Rodríguez, "Apuntes sobre sociedad y literatura hispanoamericanas en el siglo XVII", Cuardernos Americanos 4 (julio-agosto 1974): p. 142.

25. Luis Martín, Daughters of the Conquistadores: Women of the Viceroyalty of Peru (Albuquerque: University of New Mexico Press, 1983): p. 171.

26. Electa Arenal y Stacey Schlau, "Introduction - Reclaiming the Mother Tongue: History and Spiritual Politics" en: Untold Sisters - Hispanic Nuns in their Own Works (Albuquerque: University of New Mexico Press. 1989): p.9. La traducción al español es mía. También, en relación con las protestas del Padre Lambier, ver Pilar Gonzalbo Aizpuru, Las mujeres: p. 236. 
27. Susan A. Soeiro "The Social and Economic Role,": p. 223-24. Ver también a Pilar Gonzalbo aizpuru, Las mujeres: pp. 216 y 218.

28. Pilar Gonzalbo izpuru, Las mujeres pp. 218 y 219 respectivamente.

29. Susan A. Soeiro, "The Social and Economic Role"; p. 231.

30. Pilar Gonzalbo Aizpuru, Las Mujeres: pp. 243-44.

31. Pilar Gonzalbo Aizpuru, Las mujeres: pp. 33-36.

32. Asunción Lavrin, "Values and Meaning": p. 382.

33. Ruy Bloem "Teresa Margarida e o Romance Brasileiro" en: Teresa Margarita Da Silva e Orta, Aventura de Diófanes (Río de Janeiro: Imprenta Nacional, 1945): p. xv.

34. Ernesto Ennes, Dois Paulistas insignes. Teresa Margarida da Silva e Orta e o Primeiro Romance Brasileiro (Sao Paulo: Companhia Editora Nacional, 1952): 192.

35. Diego Mexía, Primera parte del Parmaso Antártico de obras amotorias (Sevilla: Alonso Rodríguez Gamarra Editor, 1608).

36. Marcelino Menéndez Pelayo, Poesía hispano-americana, II: p.163.

37. Calixto Oyuela, "Poetisa anónima peruana" en Poetas hispanoamericanos - Epoca colonial (Buenos Aires: Academia Argentina de Letras, 1949): p. 8.

38. Sor Juana Inés de la cruz, Obras completas, ed. Alfonso Méndez Plancarte (México: Fondo de Cultura Económica, Vol. I, 1951; Vol. II, 1952; Vol. III, 1955; Vol IV, 1956). Para un estudio detallado ver Octavio Paz, Sor Juana Inés de la Cruz o Las trampas de la fe (Barcelona: Seix Barral, 1982).

39. Madre Castillo Obras completas, Darío Achury Valenzuela, ed. 2 Vols. (Bogotá: Talleres Gráficos del Banco de la República, 1968).

40. Darío Achury Valenzuela, "Introducción": pp. CXCII-CXIV. Queda por comprobar si son de la autoría de la Madre Castillo, un romancillo que figura en el "Afecto $\mathrm{N}^{\circ} 46$ ", un villancico "Al nacimiento del Redentor" en el "Afecto $\mathrm{N}^{\circ} 8$ " y 3 poemas publicados en la edición de Achury Valenzuela.

41. Eugenio Salazar y Alarcón, Silva de poesía, manuscrito de la Real Academia Española de la Historia de Madrid. Ver también: Gustavo Adolfo Mejía Ricart, "Leonor Ovando" en Antología de poetas dominicanas, vol. I (Ciudad Trujillo: Imprenta de la Palabra de Santo Domingo, 1955): p.23.

42. Marcelino Menéndez Pelayo, Poesía hispano-americana, tomo I: pp. 296-99. En estas páginas están recopilados dichos textos.

43. Thomas Gage, Nueva relación que contiene los viajes de Tomás Gage en la Nueva España, Vol. II (París: Librería Rosa, 1838): pp. 26-29.

44. Ernesto Chinchilla Aguilar, Sor Juana de Maldonado y Paz-Pruebas documentales de su existencia (México: Editorial Costa Amic, 1949) y Mariano López Mayorical, Investigaciones históricas (Guatemala: Editorial del Ministerio de Educación Pública, 1958).

45. Ginés de Alvareda, ed. Antología de la poesía hispanoamericana - Venezuela, Vol. I (Madrid: Biblioteca Nueva, 1958).

46. Rubén Vargas Ugarte, "Poesías de Sor Juana de Hazaña" en: Clásicos peruanos, Vol. 5 (Lima: sin editorial, 1955): pp.148-57 y "Poesías de sor Paula de Jesús": pp.159-65. 
47. Tadea García de la Huerta, Relación de la inundación que hiso el Río Mapocho de la Ciudad de Santiago de Chile, en el Monasterio de las Carmelitas, José Toribio Medina, ed. (Santiago: Biblioteca Hispanochilena, 1899): pp. 349-54.

48. María Urzúa y Ximena Adriasola, La mujer en la literatura chilena (Santiago: Editorial Nascimiento, 1963): p.13. Ver también José Toribio Medina, La literatura femenina en Chile (Santiago: Imprenta Universitaria, 1923): p. 7.

49. Electa Arenal y Stecey Schlau, Untold Sisters: pp. 360-63 y 405-10. Contrariamente a lo que Julie Greer Johnson afirma ("The Feminine Perspective" en: Women in Colonial Spanish American Literature Literary Images (Westport, Connecticut: Greenwood Press, 1983): p.157), es obvio que además de sor Juana Inés y la Madre Castillo hubo muchas otras escritoras. Lo que hace falta es continuar investigando para sacar del olvido tantos manuscritos que permanecen empolvados en bibliotecas, colecciones privadas y conventos.

50. Algunos de esos poemas, se encuentran, por ejemplo, en folios 91-92 y 238-40.

51. José Toribio Medina, La literatura femenina en Chile: p.8. Julie Greer Johnson, Women in Colonial Spanish American Literature: p.7, observa el doble aspecto de realidad / fantasía entretejido en esos textos.

52. Rev. José Bellido, ed., Vida de la V. M.R.NM. María Anna Agueda de San Ignacio (México: Imprenta de la Biblioteca Mexicana, 1758).

53. José Bellido, Mar de gracias, contenido en el volumen de Vida de la V:NM:R:M: María Anna Agueda de San Ignacio. Libro Segundo, en que se trata de los Mysterios del Santissimo Rosario, Libro Tercero. Medidas del alma con Christo y Libro Quinto. Leyes del Amor Divino, que debe guardar la fiel, y amante Esposa de Christo forman parte del mismo. Marabillas del divino amor es otro título de la autora que aparece al principio de este tomo; sin embargo, parece ser más bien el del volumen entero pues abarca sólo el prólogo de 3 folios sin numerar y siguen las obras de ella. En publicación aparte, aunque sacado de la Vida y obras, está Devociones Varias (Puebla de los Ángeles: Oficina del Real Seminario Palafoxiano de Puebla, 1791).

54. Carlos Sigüenza y Góngora, "Varia de la V.M. Inés de la Cruz, refiriendo con sus propias palabras su prodigiosa niñez, lo que ocasionó su venida a la Nueva España y lo que en: México le sucede" en Paraíso occidental, plantado y cultivado en su magnífico real Convenio de Jesús María de México (México: Juan de Ribera, 1684): 129-52v.

55. Electa Arenal y Stacey Schlau, Untold Sisters: p.12.

56. Carta citada por Pilar Gonzalbo Alzpuru en Las mujeres: p.246.

57. Pilar Gonzalbo Aizpuru, Las mujeres: pp. 241-42. 


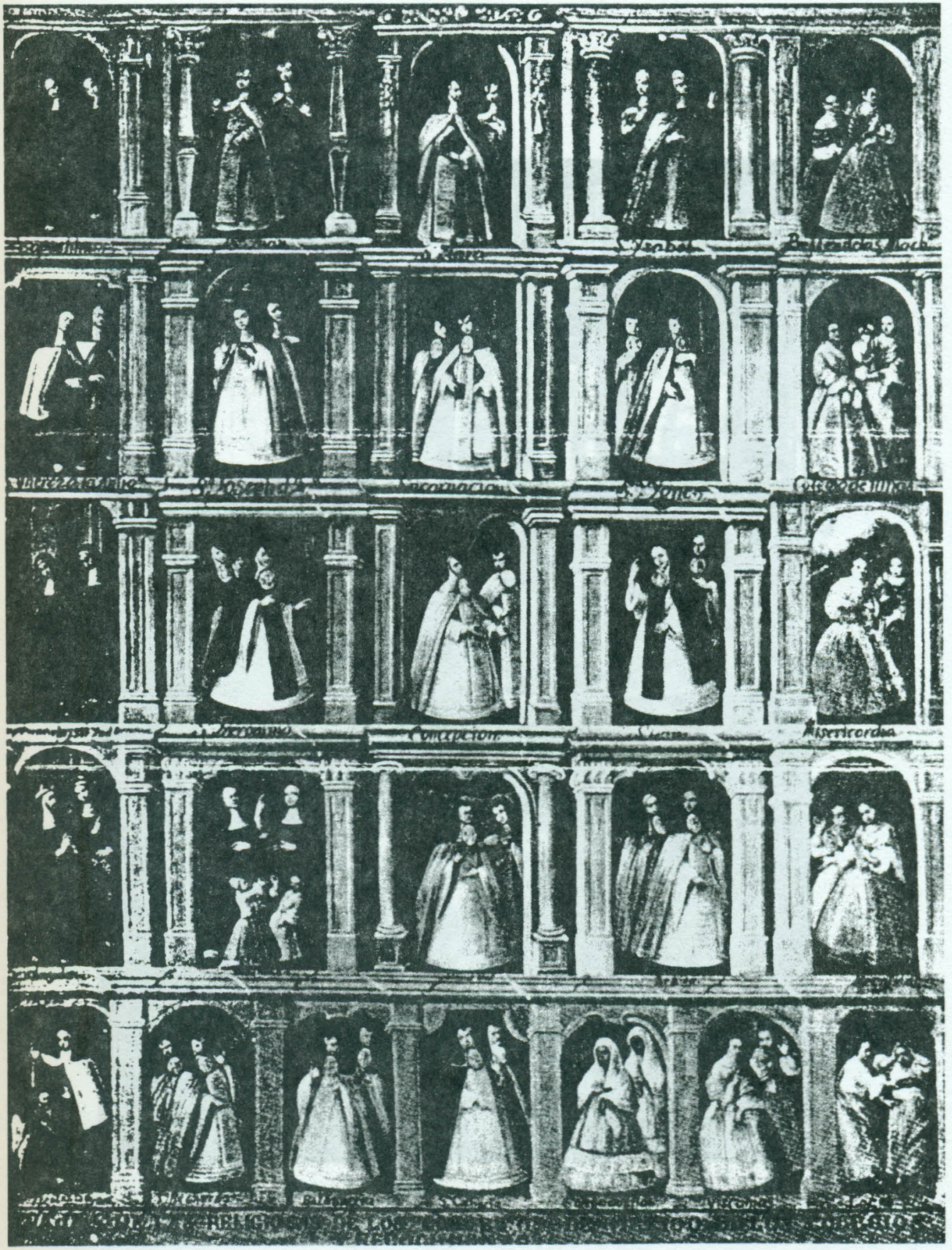

The Costumes of the nuns of the convents of Mexico. From Artes de México (México, 1960). Courtesy of the Instituto Nacional de Antropología e Historia. 


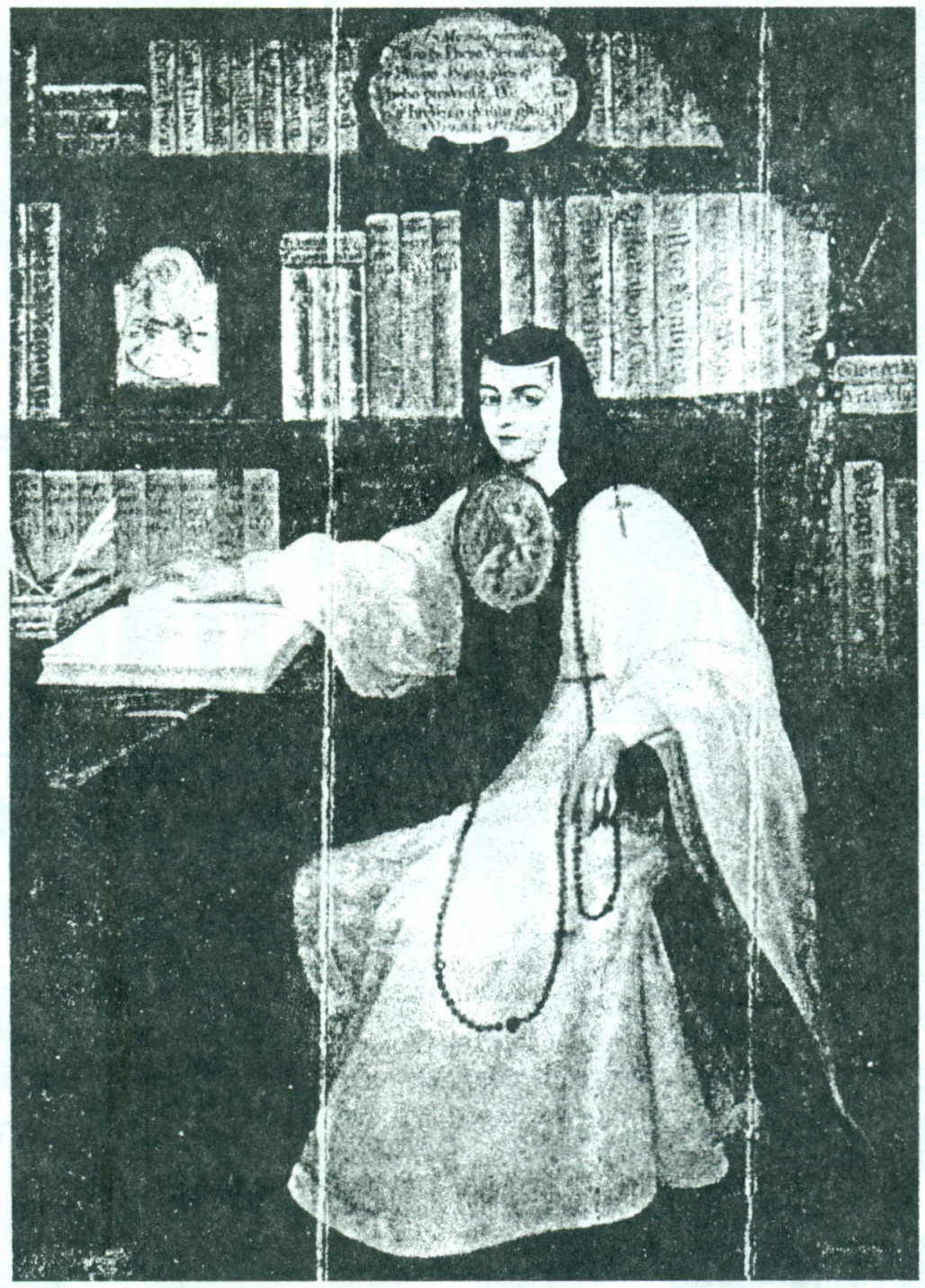

Sor Juana Inés de la Cruz (1651-1695), por Miguel Cabrera

Courtesy of the Instituto Nacional de Antrópología e Historia, CNCA. México. 

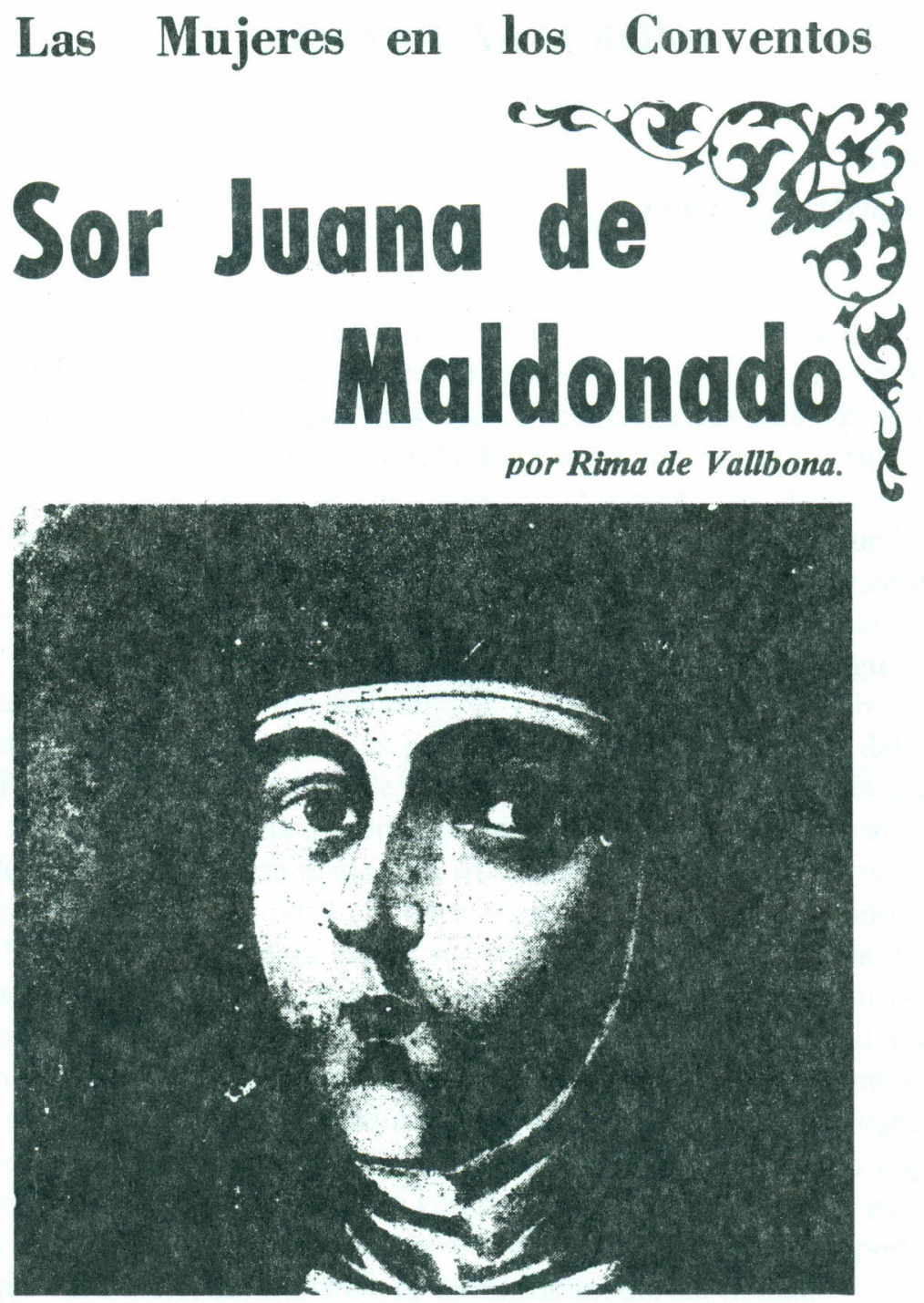
